\title{
Mathematical Model of the Impact of a Nonantibiotic Treatment for Clostridium difficile on the Endemic Prevalence of Vancomycin-Resistant Enterococci in a Hospital Setting
}

\author{
Daniel T. Grima, ${ }^{1}$ Glenn F. Webb, ${ }^{2}$ and Erika M. C. D’Agata ${ }^{3}$ \\ ${ }^{1}$ Cornerstone Research Group Inc., 204-3228 South Service Road, Burlington, ON, L7N 3H8, Canada L7N $3 H 8$ \\ ${ }^{2}$ Mathematics Department, Vanderbilt University, Nashville, TN, 37240, USA \\ ${ }^{3}$ Division of Infectious Disease, Beth Israel Deaconess Medical Center, Harvard Medical School, Lowry Building Suite 6A,
} 100 Francis Street, Boston, MA, 02215, USA

Correspondence should be addressed to Daniel T. Grima, dgrima@cornerstone-research.com

Received 23 June 2011; Accepted 4 October 2011

Academic Editor: Philip Crooke

Copyright ( $\odot 2012$ Daniel T. Grima et al. This is an open access article distributed under the Creative Commons Attribution License, which permits unrestricted use, distribution, and reproduction in any medium, provided the original work is properly cited.

\begin{abstract}
Introduction. Clostridium difficile-associated disease (CDAD) is treated using antibiotics, which often leads to the emergence of antibiotic-resistant bacteria such as vancomycin-resistant enterococci (VRE). This study estimated the impact of a non antibiotic treatment for CDAD on VRE prevalence. Methods. A previously published model describing the impact of in-hospital antibiotic use on VRE prevalence was adapted to include CDAD treatment. Simulations compared the prevalence of VRE when nonantibiotic versus antibiotic therapy was used. Results. Nonantibiotic treatment in 50\% of CDAD patients resulted in an $18 \%$ relative reduction in the prevalence of VRE colonization compared with antibiotic use only. Sensitivity analysis found the model to be most sensitive to rates of antibiotic initiation and discontinuation, prevalence of VRE in admitted patients, length of stay of colonized patients, probability of CDAD acquisition, and hand-washing compliance. Conclusion. Nonantibiotic treatment of patients hospitalized with CDAD may significantly reduce the incidence of VRE colonization.
\end{abstract}

\section{Introduction}

The bacterium Clostridium difficile is the most common cause of hospital-acquired diarrhea, accounting for up to $25 \%$ of all cases of antibiotic-associated diarrhea $[1,2]$. Rates of colonization of inpatients with $C$. difficile may be as high as $50 \%$ for patients hospitalized for more than four weeks [3]. The incidence of $C$. difficile-associated disease (CDAD) has been growing on the basis of data from the National Nosocomial Infections Surveillance system [3]. Importantly, outbreaks of severe CDAD cases have occurred in several hospitals because of the emergence of a new $C$. difficile strain with increased virulence and antibiotic resistance $[4,5]$. This more virulent bacterial strain results in more admissions to the intensive care unit, colectomies, and death than other strains $[4,5]$. A recent study reported that in the United States, the incidence of adult CDAD hospitalizations doubled from 5.5 cases per 10,000 population in 2000 to 11.2 per 10,000 cases in 2005, and the age-adjusted CDAD-related case-fatality rate rose from $1.2 \%$ in 2000 to $2.2 \%$ in 2004 [6].

Current treatment of CDAD involves antibiotic therapy with either metronidazole or vancomycin. However, there has been a growing interest in the development of nonantibiotic therapies for CDAD and other nosocomial infections in order to reduce antibiotic use in hospitals, where the goal is to limit the emergence and spread of antibiotic-resistant bacteria such as vancomycin-resistant enterococci (VRE) [7]. The use of such antibiotics can eradicate antibiotic-susceptible bacterial strains in the gastrointestinal flora, thereby allowing the overgrowth of subpopulations of antibiotic-resistant bacteria $[8,9]$. In the case of $C$. difficile treatment, both metronidazole and vancomycin are associated with the promotion of VRE. This overgrowth is evidenced by the cocolonization of $C$. 
difficile and VRE that occurs in $20 \%$ to $34 \%$ of patients, which may reflect $C$. difficile-directed antibiotic exposure as well as other common risk factors for these pathogens [10-12].

It has been suggested that nonantibiotic treatment of CDAD may offer an opportunity to reduce antibiotic use in hospitals and could ultimately decrease the prevalence and burden of VRE. For example, although ultimately unsuccessful, the enterotoxin-binding polymer tolevamer (Genzyme, Inc.) was investigated for the treatment of CDAD in 2008 $[13,14]$. More recently, a number of small studies have reported on the successful use of fecal donor instillation therapy (FDIT) for the treatment of patients with CDAD [15-17]. Used for decades in some hospitals, only recently has the effectiveness of this therapy been documented in the literature. In a retrospective study of 40 patients with recurrent $\mathrm{CDAD}, 83 \%$ of patients were successfully treated with FDIT, having met the study's endpoint of no further hospital contact due to CDAD symptoms within 80 days of therapy. While in the study's protocol patients were treated with metronidazole or vancomycin until reduction of symptoms, all antimicrobial therapy was discontinued on the evening prior to donor stool transplantation [18].

The objective of this study was to estimate the potential impact of a nonantibiotic treatment for $\mathrm{CDAD}$ on the prevalence of VRE within a hospital setting. A mathematical model was used to estimate and compare the prevalence of VRE with current antibiotic therapies for CDAD versus nonantibiotic therapies such as FDIT.

\section{Methods}

The current model (Appendix) extends a previously published model by D'Agata and colleagues (2005) that described the impact of antibiotic use on VRE prevalence within a hospital setting [19]. The model considers the admission of patients with and without VRE to a hospital and their consequent risks of CDAD and VRE acquisition. Since VRE is predominantly spread from patient-to-patient via the contaminated hands or clothes of health care workers (HCWs), the complex interactions between patients and HCWs were also incorporated into the model. The model describes the transmission dynamics of VRE in a 400-bed hospital. The original model compartmentalized patients into those receiving (right side of Figure 1) and not receiving (left side of Figure 1) antibiotics, and those who were VREcolonized (bottom boxes in Figure 1) and those who were not (top boxes in Figure 1). The original model was then extended to include CDAD status. Each of the four original boxes was divided into an outer and inner box, and CDAD positive $(\mathrm{CDAD}+)$ patients were included in the inner boxes $3,4,5$, and 6 . These boxes included CDAD patients who were not receiving antibiotics and were either uncolonized (Box 3) or colonized (Box 5) with VRE as well as individuals who were receiving antibiotics and were either uncolonized (Box 4) or colonized (Box 6) with VRE.

All model parameter values are provided in Table 1. Except where noted below, the same values from D'Agata and colleagues' model were used. These values were originally obtained from pharmacy records and an observational HCW study at Beth Israel Deaconess Medical Center [19]. The spread of VRE between patients and associated movement between compartments occurred because of HCWs whose hands were contaminated with VRE after contact with a colonized patient (Figure 2). The interaction between patients and HCWs included the number of contacts with a patient during routine patient care and compliance with hand hygiene (Table 1). The latter was an important inclusion, since hand hygiene will remove VRE from HCWs' hands and thereby prevent transmission of VRE to patients. It was assumed that patients who were colonized with VRE were on contact precautions and therefore less likely to contaminate HCWs. The implementation of these precautions is standard practice in hospital settings and requires HCWs to don gloves and gowns prior to entering the room of a VREcolonized patient in order to prevent HCW contamination [20].

The movement between compartments was also influenced by the proportion of patients who were started on antibiotics or in whom antibiotics were discontinued. It was assumed that patients receiving antibiotics were more likely to contaminate an HCW, since studies have documented that antibiotic exposure results in increased VRE stool densities and a greater likelihood of skin contamination (Table 1) [9]. Although contamination of HCWs' clothes and inanimate surfaces contribute to VRE dissemination, these factors were omitted in order to simplify the model [21].

The probability of colonization per contact between uncolonized CDAD patients on antibiotics and contaminated HCW (0.16) was based on an assumption that contact precautions for $\mathrm{CDAD}+$ patients would decrease the probability of contamination by $60 \%$ compared to patients without CDAD [22]. These values were obtained from studies focusing on Acinetobacter spp. The daily probability of patients on antibiotics to transit to CDAD+ $(15 / 14=$ $1.07 \%$ ) was based on an overall risk of CDAD infection for antibiotic-treated patients of $15 \%$ and an average length of stay of 14 days, as per the original model [19]. The daily probability of CDAD resolution of $27.03 \%=100(3 \times 9+$ $10 \times 0.1$ ) was based on the assumption that $90 \%$ of CDAD cases resolve within 3 days and $10 \%$ require 10 days [23].

The model was run until it reached a steady state, and the total numbers of patients in each state was compared in two scenarios: (1) all patients received antibiotics for treatment of CDAD in hospital and (2) a subgroup of CDAD patients received a nonantibiotic treatment for CDAD with equal efficacy to antibiotic therapy. First, to simulate current care for CDAD with antibiotic therapy and the lack of a nonantibiotic treatment option, the transition probabilities for entry into boxes 3 and 5 were set to zero. Second, to simulate the impact of avoiding antibiotic exposure with the use of a nonantibiotic therapy for CDAD, $50 \%$ of patients acquiring $\mathrm{CDAD}$ were assumed to discontinue antibiotics and move to boxes 3 and 5 . 


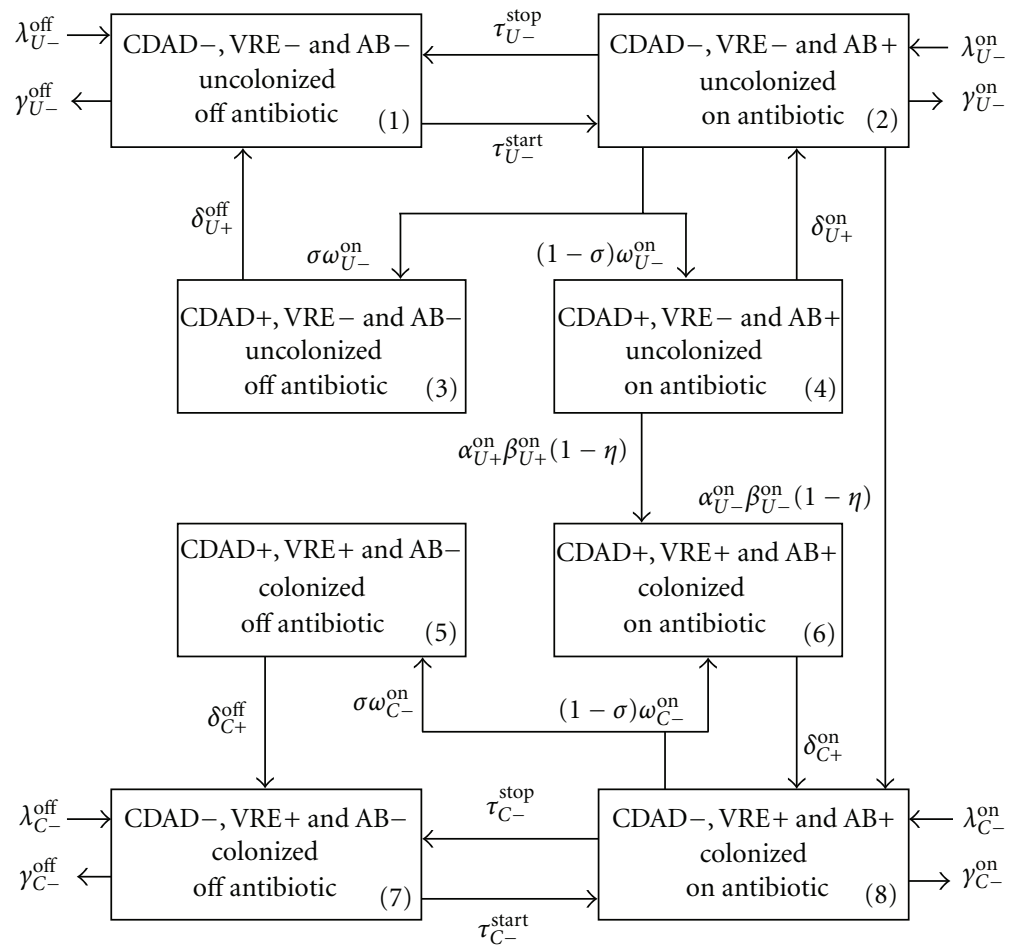

FIGURE 1: Schematic diagram of the patient compartments. CDAD = clostridium difficile-associated disease; CDAD $+=$ clostridium difficileassociated disease positive; $\mathrm{CDAD}-=$ clostridium difficile-associated disease negative; $\mathrm{VRE}=$ vancomycin-resistant enterococci; $\mathrm{VRE}+=$ vancomycin-resistant enterococci colonized; VRE- = vancomycin-resistant enterococci not colonized; $\mathrm{AB}-=$ off antibiotics; $\mathrm{AB}+=$ on antibiotics; $\lambda_{U-}^{\text {off }}=\mathrm{CDAD}-$, uncolonized, off antibiotic: admission rate; $\gamma_{U-}^{\text {off }}=\mathrm{CDAD}-$, uncolonized, off antibiotic: average length of stay; $\lambda_{U-}^{\text {on }}=$ CDAD - , uncolonized, on antibiotic: admission rate; $\gamma_{U-}^{\text {on }}=\mathrm{CDAD}-$, uncolonized, on antibiotic: average length of stay; $\tau_{U-}^{\text {stop }}=\mathrm{CDAD}-$, uncolonized, on antibiotic: stop antibiotic; $\tau_{U-}^{\text {start }}=\mathrm{CDAD}-$, uncolonized, off antibiotic: start antibiotic; $\delta_{U+}^{\text {off }}=\mathrm{CDAD}+$, uncolonized, off antibiotic: transit to $\mathrm{CDAD}-; \sigma=$ fraction of $\mathrm{AB}$ patients that transit to $\mathrm{CDAD}+$ and stop $\mathrm{AB} ; \omega_{U-}^{\mathrm{on}}=\mathrm{CDAD}-$, uncolonized, on antibiotic: transit to $\mathrm{CDAD}+; \delta_{U+}^{\mathrm{on}}=\mathrm{CDAD}+$, uncolonized, on antibiotic: transit to CDAD-; $\alpha_{U+}^{\mathrm{on}}=$ average number of contacts between uncolonized $\mathrm{CDAD}-$ patients on antibiotic and HCW; $\beta_{U+}^{\mathrm{on}}=$ probability of colonization per contact between uncolonized CDAD + patient on antibiotic and contaminated HCW; $\alpha_{U-}^{\text {on }}=$ average number of contacts between uncolonized CDAD + patients on antibiotic and $\mathrm{HCW} ; \beta_{U-}^{\text {on }}=$ probability of colonization per contact between uncolonized CDAD - patient on antibiotic and contaminated $\mathrm{HCW} ; \eta=$ hand washing compliance factor between 0 and $1 ; \delta_{C+}^{\text {off }}=\mathrm{CDAD}+$, colonized, off antibiotic: transit to CDAD $-; \omega_{C-}^{\text {on }}=\mathrm{CDAD}-$, colonized, on antibiotic: transit to CDAD $+; \delta_{C+}^{\text {on }}$ $=\mathrm{CDAD}+$, colonized, on antibiotic: transit to $\mathrm{CDAD}-; \lambda_{C-}^{\text {off }}=\mathrm{CDAD}-$, colonized, off antibiotic: admission rate; $\tau_{C-}^{\text {stop }}=\mathrm{CDAD}-$, colonized, on antibiotic: stop antibiotic; $\lambda_{C-}^{\text {on }}=\mathrm{CDAD}-$, colonized, on antibiotic: admission rate; $\tau_{C-}^{\text {start }}=\mathrm{CDAD}-$, colonized, off antibiotic: start antibiotic; $\gamma_{C-}^{\text {on }}=\mathrm{CDAD}-$, colonized, on antibiotic: average length of stay; $\gamma_{C-}^{\text {off }}=\mathrm{CDAD}-$, colonized, off antibiotic: average length of stay.

\section{Sensitivity Analyses}

Univariate sensitivity analyses were conducted for percent of $\mathrm{CDAD}+$ patients that stop antibiotics and start a nonantibiotic treatment, number of colonized patients admitted per day, length of stay of colonized patients, percentage of handwashing compliance, percentage of uncolonized patients on antibiotics that become CDAD+, and time to symptoms resolution of colonized $\mathrm{CDAD}+$ patients on antibiotics.

\section{Results}

The distributions of patients in each steady state under both scenarios are summarized in Table 2. Under the first scenario, where antibiotics were used for all CDAD+ patients $(\sigma=$ 0.0 ), of the approximately 400 patients in the steady state, $60(15.0 \%)$ were colonized with VRE, $194(48.5 \%)$ were on antibiotics, and $6(1.5 \%)$ were $\mathrm{CDAD}+$, all of whom were on antibiotics (Table 2). Under the second scenario, where $50 \%$ of CDAD + patients discontinued antibiotics in favor of a nonantibiotic treatment $(\sigma=0.5)$, VRE colonization was reduced. In this scenario, the total number of patients on antibiotics declined to $185(46.3 \%)$ and the number of $\mathrm{CDAD}+$ patients receiving antibiotics declined to $3(0.75 \%)$. The total number of patients who were VRE-colonized at any given time declined from 60 to 49 (from $15.0 \%$ down to $12.25 \%$ ), an absolute decline of $2.75 \%$ and a relative decline of $18 \%$. Assuming a 400 -bed hospital and 25 patients per bed a year, this outcome translates into 275 avoided cases of VRE colonization per year.

Results of the sensitivity analyses are presented in Figure 2. In all analyses, the nonantibiotic use scenario was associated with a lower prevalence of VRE colonization. In the nonantibiotic scenario, the percentage of VRE-colonized 
TABLE 1: Parameters used in modeling the effect of antibiotic versus nonantibiotic treatment of CDAD on VRE colonization.

\begin{tabular}{|c|c|c|}
\hline Parameter & Patients & Value \\
\hline$N p$ & number of patients in the hospital & 400 \\
\hline$\rho$ & ratio of patients to $\mathrm{HCW}$ & 4 \\
\hline$\lambda_{U-}^{\text {off }}$ & CDAD-, uncolonized, off antibiotic: admission rate & 50.1 per day \\
\hline$\gamma_{U-}^{\text {off }}$ & CDAD-, uncolonized, off antibiotic: average length of stay & 5 days \\
\hline$\lambda_{U-}^{\text {on }}$ & CDAD-, uncolonized, on antibiotic: admission rate & 2.505 per day \\
\hline$\gamma_{U-}^{\text {on }}$ & CDAD-, uncolonized, on antibiotic: average length of stay & 14 days \\
\hline$\lambda_{C-}^{\text {off }}$ & CDAD-, colonized, off antibiotic: admission rate & 0.334 per day \\
\hline$\gamma_{C-}^{\text {off }}$ & CDAD-, colonized, off antibiotic: average length of stay & 28 days \\
\hline$\lambda_{C-}^{\text {on }}$ & CDAD-, colonized, on antibiotic: admission rate & 0.501 per day \\
\hline$\gamma_{C-}^{\text {on }}$ & CDAD-, colonized, on antibiotic: average length of stay & 28 days \\
\hline$\tau_{U-}^{\text {stop }}$ & CDAD-, uncolonized, on antibiotic: stop antibiotic & $15 \%$ per day \\
\hline$\tau_{U-}^{\text {start }}$ & CDAD-, uncolonized, off antibiotic: start antibiotic & $15 \%$ per day \\
\hline$\tau_{C-}^{\text {stop }}$ & CDAD-, colonized, on antibiotic: stop antibiotic & $4 \%$ per day \\
\hline$\tau_{C-}^{\text {start }}$ & CDAD-, colonized, off antibiotic: start antibiotic & $16 \%$ per day \\
\hline$\sigma$ & fraction of $\mathrm{CDAD}+$, on antibiotic: stop antibiotic & 0.5 \\
\hline$\alpha_{U+}^{\text {on }}$ & $\begin{array}{l}\text { average number of contacts between uncolonized } \\
\text { CDAD- patients on antibiotic and HCW }\end{array}$ & 8 per day \\
\hline$\alpha_{U-}^{\text {on }}$ & $\begin{array}{l}\text { average number of contacts between uncolonized } \\
\text { CDAD+ patients on antibiotic and HCW }\end{array}$ & 8 per day \\
\hline$\beta_{U+}^{\text {on }}$ & $\begin{array}{l}\text { probability of colonization per contact between uncolonized } \\
\text { CDAD+ patient on antibiotic and contaminated HCW }\end{array}$ & 0.024 \\
\hline$\beta_{U-}^{\text {on }}$ & $\begin{array}{l}\text { probability of colonization per contact between uncolonized } \\
\text { CDAD- patient on antibiotic and contaminated HCW }\end{array}$ & 0.06 \\
\hline$\omega_{U-}^{\mathrm{on}}$ & CDAD-, uncolonized, on antibiotic: transit to CDAD+ & $1.07 \%$ per day \\
\hline$\omega_{C-}^{\text {on }}$ & CDAD-, colonized, on antibiotic: transit to CDAD+ & $1.07 \%$ per day \\
\hline$\delta_{C+}^{\text {on }}$ & $\mathrm{CDAD}+$, colonized, on antibiotic: transit to CDAD- & $27 \%$ per day \\
\hline$\delta_{C+}^{\text {off }}$ & $\mathrm{CDAD}+$, colonized, off antibiotic: transit to CDAD- & $27 \%$ per day \\
\hline$\delta_{U+}^{\text {on }}$ & $\mathrm{CDAD}+$, uncolonized, on antibiotic: transit to CDAD- & $27 \%$ per day \\
\hline$\delta_{U+}^{\text {off }}$ & CDAD+, uncolonized, off antibiotic: transit to CDAD- & $27 \%$ per day \\
\hline$\sigma$ & fraction of $\mathrm{AB}$ patients that transit to $\mathrm{CDAD}+$ and stop $\mathrm{AB}$ & 0.0 or 0.5 \\
\hline Parameter & Health care workers & Value \\
\hline$\alpha_{C+}$ & average number of contacts between $\mathrm{HCW}$ and colonized CDAD + patients & 10 per day \\
\hline$\alpha_{C-}$ & average number of contacts between HCW and colonized CDAD+ patients & 10 per day \\
\hline$\kappa_{-}^{\text {on }}$ & $\begin{array}{l}\text { probability of contamination per contact between uncontaminated } \\
\text { HCW and colonized CDAD- patient on antibiotic }\end{array}$ & 0.4 \\
\hline$\kappa_{-}^{\text {off }}$ & $\begin{array}{l}\text { probability of contamination per contact between uncontaminated } \\
\text { HCW and colonized CDAD- patient off antibiotic }\end{array}$ & 0.4 \\
\hline$\kappa_{+}^{\text {on }}$ & $\begin{array}{l}\text { probability of contamination per contact between uncontaminated } \\
\text { HCW and colonized CDAD + patient on antibiotic }\end{array}$ & 0.16 \\
\hline$\kappa_{+}^{\mathrm{off}}$ & $\begin{array}{l}\text { probability of contamination per contact between uncontaminated } \\
\text { HCW and colonized CDAD+ patient off antibiotic }\end{array}$ & 0.16 \\
\hline$\mu$ & average duration of $\mathrm{HCW}$ contamination & 48 minutes \\
\hline$\eta$ & hand-washing compliance factor between 0 and 1 & 0.6 \\
\hline
\end{tabular}

patients decreased notably if the percentage of CDAD+ patients that stop antibiotics and start a nonantibiotic regiment increased (Figure 2(a)), the hand-washing compliance percentage increased (Figure 2(d)), or the percentage of uncolonized patients on antibiotics that become CDAD+ increased (Figure 2(e)). With both antibiotic and nonantibiotic therapies, the percentage of VRE-colonized patients increased notably when the number of colonized patients admitted per day increased (Figure 2(b)) or the length of stay of colonized patients increased (Figure 2(c)). 


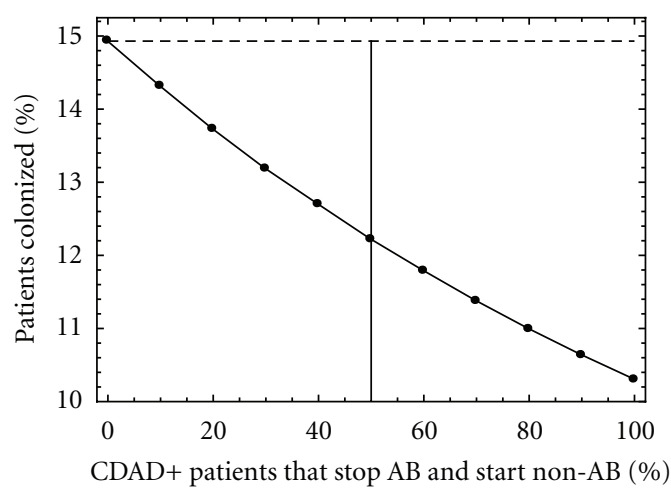

(a)

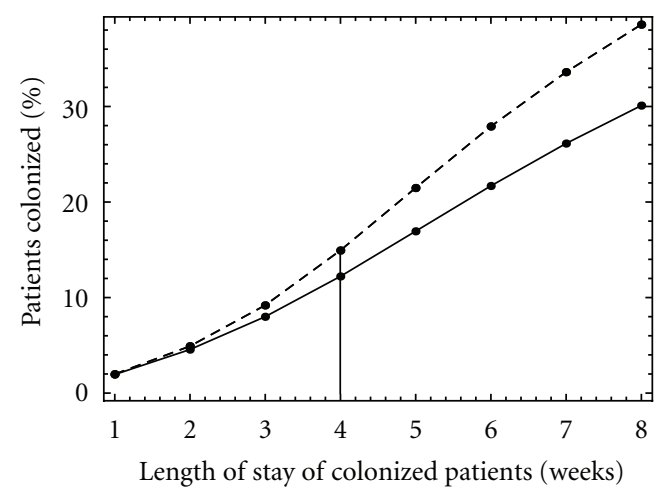

(c)

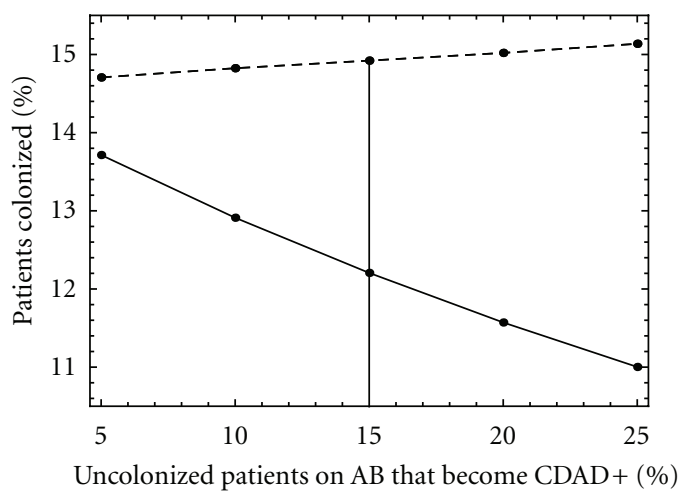

(e)

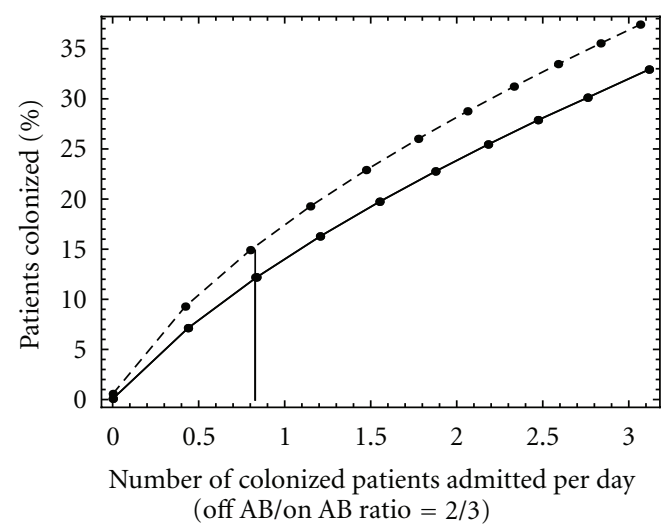

(b)

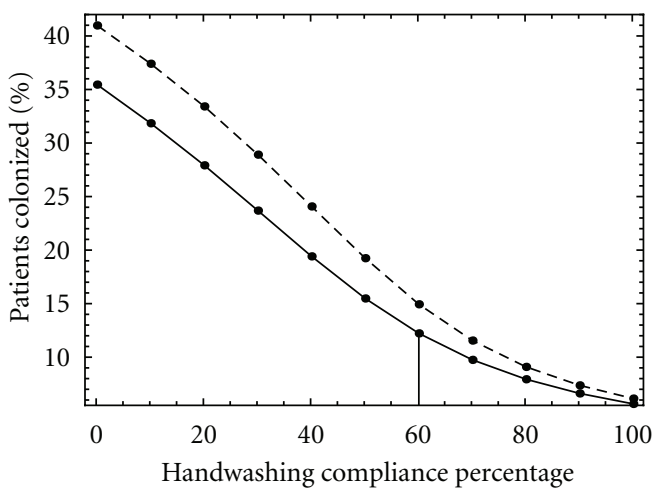

(d)

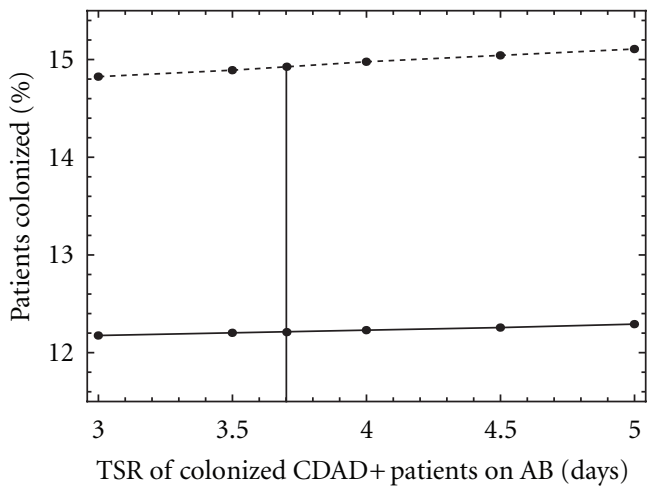

(f)

FIGURE 2: Sensitivity analyses of the model parameters. Dashed lines: Scenario 1 (use of AB only); Solid lines: Scenario 2 (use of non-antimicrobial); Vertical line: baseline values; (a) Percentage of CDAD+ patients that stop $\mathrm{AB}$ and start non-AB (baseline $=50 \%, \sigma=0.5)$; (b) Number of colonized patients admitted per day in the ratio $\lambda_{C-}^{\text {off }} / \lambda_{C-}^{\text {on }}=2 / 3$ (baseline $\lambda_{C-}^{\text {off }}=0.33, \lambda_{C-}^{\text {on }}=0.5$ ); (c) Length of stay of colonized patients in weeks (baseline $=4$ weeks, $=\gamma_{C-}^{\text {off }} / \gamma_{C-}^{\text {on }}=1 / 28$ ); (d) Hand-washing compliance percentage (baseline $\left.=60 \%, \eta=0.6\right)$; (e) Percentage of uncolonized and colonized patients on $\mathrm{AB}$ (held equal) that become CDAD+ (baseline $=15 \%, \omega_{U-}^{\mathrm{on}}=\omega_{C-}^{\mathrm{on}}=-\log (0.9893)$ ); (f) Time to symptoms resolution (TSR) of colonized $\mathrm{CDAD}+$ patients on $\mathrm{AB}$ in days (baseline $=3.7$ days, $\delta_{C+}^{\text {on }}=-\log (0.73)$ ); $\mathrm{AB}=\mathrm{antibiotic}$; $\mathrm{CDAD}=$ clostridium difficile-associated disease; non- $\mathrm{AB}=$ nonantibiotic; $\lambda_{C-}^{\text {off }}=\mathrm{CDAD}-$, colonized, off antibiotic: admission rate; $\gamma_{C-}^{\text {on }}=$ $\mathrm{CDAD}-$, colonized, on antibiotic: average length of stay; $\omega_{U-}^{\mathrm{on}}=\mathrm{CDAD}-$, uncolonized, on antibiotic: transit to $\mathrm{CDAD}+; \omega_{C-}^{\mathrm{on}}=\mathrm{CDAD}-$, colonized, on antibiotic: transit to CDAD $+; \gamma_{C-}^{\text {off }}=\mathrm{CDAD}-$, colonized, off antibiotic: average length of stay; $\lambda_{C-}^{\text {on }}=\mathrm{CDAD}-$, colonized, on antibiotic: admission rate.

\section{Discussion}

The association between antibiotic use in hospitals and the colonization of patients with antibiotic-resistant bacteria such as VRE is well documented [24]. This finding has spurred research into nonantibiotic options for the treatment of nosocomial infections such as CDAD. For example, the anionic polymer tolevamer (Genzyme, Inc.) was developed 
TABLE 2: Distribution of patients and health care workers with or without VRE colonization on the basis of antibiotic versus nonantibiotic treatment of CDAD.

\begin{tabular}{|c|c|c|c|c|c|}
\hline $\begin{array}{l}\text { Patient colonization/HCW } \\
\text { contamination status }\end{array}$ & AB status & $\begin{array}{l}\text { Model with } \mathrm{AB} \\
\text { only }\end{array}$ & $\begin{array}{c}\text { Model with } \\
\mathrm{AB} \text { and } \\
\text { non- } \mathrm{AB}\end{array}$ & $\begin{array}{l}\text { Change with } \\
\text { non-AB }\end{array}$ & $\begin{array}{c}\text { Difference } \\
\text { with non-AB }\end{array}$ \\
\hline \multicolumn{6}{|c|}{ Patient Steady State Values } \\
\hline uncolonized CDAD- patient & off & 195.176 & 202.555 & increases & 7.390 \\
\hline uncolonized CDAD- patient & on & 140.383 & 143.553 & increases & 3.170 \\
\hline colonized CDAD- patient & off & 10.7197 & 9.0598 & decreases & -1.6599 \\
\hline colonized CDAD- patient & on & 47.3343 & 38.4389 & decreases & -8.8954 \\
\hline uncolonized CDAD+ patient & on & 4.7467 & 2.4307 & decreases & -2.3160 \\
\hline colonized CDAD+ patient & on & 1.6721 & 0.6798 & decreases & -0.9923 \\
\hline uncolonized CDAD+ patient & off & 0.0 & 2.4535 & increases & 2.4535 \\
\hline colonized CDAD+ patient & off & 0.0 & 0.6570 & increases & 0.6570 \\
\hline \multicolumn{6}{|c|}{ Patient Totals at Steady State } \\
\hline total patients & & 400.03 & 399.828 & & \\
\hline Total VRE-colonized patients & & 59.7361 & 48.83555 & decreases & -10.8905 \\
\hline total CDAD+ patients & & 6.4188 & 6.2210 & decreases & -0.1978 \\
\hline total $\mathrm{CDAD}+$ patients on $\mathrm{AB}$ & & 6.4188 & 3.1105 & decreases & -3.3083 \\
\hline total patients on $\mathrm{AB}$ & & 194.136 & 185.102 & decreases & -9.034 \\
\hline \multicolumn{6}{|c|}{ Percentage of Patients Colonized at Steady State } \\
\hline$\%$ of all patients colonized & & $14.930 \%$ & $12.214 \%$ & decreases & $-2.716 \%$ \\
\hline$\%$ CDAD - patients colonized & & $14.749 \%$ & $12.068 \%$ & increases & $-2.681 \%$ \\
\hline$\%$ CDAD + patients colonized & & $26.050 \%$ & $21.488 \%$ & decreases & $-4.562 \%$ \\
\hline \multicolumn{6}{|c|}{ HCW Steady State Values } \\
\hline uncontaminated HCW & & 95.3347 & 96.1513 & increases & 0.8166 \\
\hline contaminated HCW & & 4.6653 & 3.8487 & decreases & -0.8166 \\
\hline
\end{tabular}

$\mathrm{CDAD}=$ Clostridium difficile-associated disease; $\mathrm{VRE}=$ vancomycin-resistant enterococci; $\mathrm{HCW}=$ health care worker; CDAD $+=$ Clostridium difficileassociated disease positive; $\mathrm{CDAD}-=$ clostridium difficile-associated disease negative; $\mathrm{AB}=$ antibiotic.

to neutralize clostridial toxins without adversely affecting the normal flora of the gut $[13,14]$. Results from a phase III trial revealed that the recurrence rate of CDAD was reduced significantly when compared with vancomycin and metronidazole; however, the study failed to meet its primary endpoint due to the high dropout rate associated with tolevamer [25]. As the development of the therapy was subsequently halted, its impact on the prevalence of VRE is unknown.

More recent publications have reported on the safety and effectiveness of FDIT for the treatment of CDAD. This therapy involves the introduction of a stool transplant into the duodenum or colon via a gastroscope or colonoscope, respectively, to repopulate the microflora of the bowel [15, 16]. Although used for decades, particularly in Scandinavian countries, the clinical data describing FDIT are limited; still, available reports suggest that the treatment is safe and effective even in patients with refractory CDAD [15-17]. A recent review of 16 publications concluded that $91 \%$ of all reported patients with recurrent $C$. difficile infection who were treated with FDIT were cured after one or more infusions [26]. The impact of FDIT on the prevalence of VRE, however, remains uncertain.

The availability of a nonantibiotic treatment for CDAD raises interesting questions regarding its possible impact on the prevalence of VRE compared with conventional antibiotic therapy. Our study adapted an existing model of VRE prevalence within a hospital setting to study the possible effect of the introduction of a nonantibiotic treatment for CDAD. The study found that treatment of $50 \%$ of patients with CDAD with a nonantibiotic regimen resulted in an approximately $2.75 \%$ absolute reduction (18\% relative reduction) in VRE-colonized patients compared with a scenario, whereby all CDAD patients received antibiotics.

This reduction in VRE prevalence represents a meaningful impact within a hospital, given the costs associated with the management of VRE-colonized patients and potential clinical impact of VRE infections. For a 400-bed hospital, the analysis estimated a reduction of 275 cases of VRE colonization. On the basis of an average cost of contact precautions of USD \$2,694.01 (CDN \$3,191.83 at exchange of 0.844034), this would result in cost savings of approximately USD $\$ 740,800$ a year [27]. A small reduction in VRE prevalence may also have a substantial impact on the clinical outcome and costs of VRE infections. VRE infection has been observed to occur in as many as $11.1 \%$ of VRE-colonized patients [12]. The cost to treat a patient with a VRE infection has been reported as approximately USD \$13,000 [28]. The mortality rate for a VRE infection has been estimated as 39\% to $49 \%$ [29]. On the basis of the current model, an $18 \%$ reduction in VRE prevalence could avert as many as 30.5 cases of VRE 
infection for a 400-bed hospital. This reduction in VRE infections could lead to a cost savings of USD $\$ 396,500$ per year and could prevent up to $15 \mathrm{VRE}$-associated deaths annually.

Note that the current study excludes other types of antibiotic-resistant bacteria such as methicillin-resistant Staphylococcus aureus, which would also be affected by reduced use of antibiotics within a hospital. As such, it is likely that the study underestimates the extent of the impact of a nonantibiotic treatment for CDAD.

The study shares limitations that are common to all mathematical models in that it requires the use of data from multiple sources to model processes that have not been fully observed. The validity of such a model comes from the use of realistic assumptions and clinical review. In this case, the study was derived from a published model that was based on patterns of VRE transmission that have been widely studied and baseline parameters that were obtained from actual hospital data [19]. Given the variability that may exist for some of the model parameters, extensive sensitivity analyses were conducted. These sensitivity analyses revealed that the following variables had the most influence on the prevalence of VRE: the rate of antibiotic initiation or discontinuation in $\mathrm{CDAD}$ negative and positive patients, the length of stay of VRE-colonized patients, hand-washing compliance, and the number of VRE-colonized patients admitted per day. All of these variables would be expected to differ among hospitals given local infection control policies and the endemic rates of VRE colonization in the community.

\section{Conclusions}

Use of a nonantibiotic treatment in hospital patients with CDAD may significantly reduce the colonization of patients with VRE and the associated burden of disease.

\section{Appendix}

The CDAD epidemic within the hospital setting is described mathematically by a system of nonlinear ordinary differential equations. The populations under consideration are as follows: uncolonized CDAD - patients off antibiotics $\left(P_{U-}^{\text {off }}\right)$, uncolonized CDAD- patients on antibiotics $\left(P_{U-}^{\text {on }}\right)$, colonized CDAD - patients off antibiotics $\left(P_{C-}^{\text {off }}\right)$, colonized $\mathrm{CDAD}-$ patients on antibiotics $\left(P_{C-}^{\text {on }}\right)$, uncolonized $\mathrm{CDAD}^{+}$ patients off antibiotics $\left(P_{U+}^{\text {off }}\right)$, uncolonized $\mathrm{CDAD}^{+}$patients on antibiotics $\left(P_{U+}^{\text {on }}\right)$, colonized $\mathrm{CDAD}^{+}$patients off antibiotics $\left(P_{C+}^{\text {off }}\right)$, colonized $\mathrm{CDAD}^{+}$patients on antibiotics $\left(P_{C+}^{\text {on }}\right)$, uncontaminated health care workers $\left(H_{U}\right)$, and contaminated health care workers $\left(H_{C}\right)$. Each population is a function of time $(t)$ in days, and each population has initial conditions prescribed at time 0 . The rates of change of these populations are governed by

$$
\begin{aligned}
\frac{d P_{U-}^{\mathrm{off}}}{d t}= & \lambda_{U-}^{\mathrm{off}}-\tau_{U-}^{\mathrm{start}} P_{U-}^{\mathrm{off}}+\tau_{U-}^{\mathrm{stop}} P_{U-}^{\mathrm{on}}-\gamma_{U-}^{\mathrm{off}} P_{U-}^{\mathrm{off}}+\delta_{U+}^{\mathrm{off}} P_{U+}^{\mathrm{off}}, \\
\frac{d P_{U-}^{\mathrm{on}}}{d t}= & \lambda_{U-}^{\mathrm{on}}-\tau_{U-}^{\mathrm{stop}} P_{U-}^{\mathrm{on}}+\tau_{U-}^{\mathrm{start}} P_{U-}^{\mathrm{off}}-\omega_{U-}^{\mathrm{on}} P_{U-}^{\mathrm{on}} \\
& -\alpha_{U-}^{\mathrm{on}} \beta_{U-}^{\mathrm{on}}(1-\eta) \frac{H_{C}}{N h} P_{U-}^{\mathrm{on}}+\delta_{U+}^{\mathrm{on}} P_{U+}^{\mathrm{on}}-\gamma_{U-}^{\mathrm{on}} P_{U-}^{\mathrm{on}},
\end{aligned}
$$

$$
\begin{aligned}
& \frac{d P_{U+}^{\mathrm{off}}}{d t}=\sigma \omega_{U-}^{\mathrm{on}} P_{U-}^{\mathrm{on}}-\delta_{U+}^{\mathrm{off}} P_{U+}^{\mathrm{off}}, \\
& \frac{d P_{U+}^{\text {on }}}{d t}=(1-\sigma) \omega_{U-}^{\text {on }} P_{U-}^{\text {on }}-\delta_{U+}^{\text {on }} P_{U+}^{\text {on }} \\
& -\alpha_{U+}^{\mathrm{on}} \beta_{U+}^{\mathrm{on}}(1-\eta) \frac{H_{C}}{N h} P_{U+}^{\mathrm{on}} \\
& \frac{d P_{C+}^{\mathrm{off}}}{d t}=\sigma \omega_{C-}^{\mathrm{on}} P_{C-}^{\mathrm{on}}-\delta_{C+}^{\mathrm{off}} P_{C+}^{\mathrm{off}} \text {, } \\
& \frac{d P_{C+}^{\mathrm{on}}}{d t}=(1-\sigma) \omega_{C-}^{\mathrm{on}} P_{C-}^{\mathrm{on}}-\delta_{C+}^{\mathrm{on}} P_{C+}^{\mathrm{on}} \\
& +\alpha_{U+}^{\text {on }} \beta_{U+}^{\text {on }}(1-\eta) \frac{H_{C}}{N h} P_{U+}^{\text {on }}, \\
& \frac{d P_{C-}^{\text {off }}}{d t}=\lambda_{C-}^{\text {off }}-\tau_{C-}^{\text {start }} P_{C-}^{\text {off }}+\tau_{C-}^{\text {stop }} P_{C-}^{\text {on }} \\
& -\gamma_{C-}^{\text {off }} P_{C-}^{\text {off }}+\delta_{C+}^{\text {off }} P_{C+}^{\text {off }} \text {, } \\
& \frac{d P_{C-}^{\text {on }}}{d t}=\lambda_{C-}^{\text {on }}-\tau_{C-}^{\text {stop }} P_{C-}^{\text {on }}+\tau_{C-}^{\text {start }} P_{C-}^{\text {off }}-\omega_{C-}^{\text {on }} P_{C-}^{\text {on }} \\
& +\alpha_{U-}^{\mathrm{on}} \beta_{\mathrm{U}-}^{\mathrm{on}}(1-\eta) \frac{H_{C}}{N h} P_{U-}^{\mathrm{on}}+\delta_{C+}^{\mathrm{on}} P_{C+}^{\mathrm{on}}-\gamma_{C-}^{\mathrm{on}} P_{C-}^{\mathrm{on}} \text {, } \\
& \frac{d H_{U}}{d t}=-\left[\alpha_{C-} \kappa_{-}^{\mathrm{off}}\left(\frac{P_{C-}^{\mathrm{off}}}{N p}\right)+\alpha_{C-} \kappa_{-}^{\mathrm{on}}\left(\frac{P_{C-}^{\mathrm{on}}}{N p}\right)\right. \\
& \left.+\alpha_{C+} \kappa_{+}^{\text {on }}\left(\frac{P_{C+}^{\text {on }}}{N p}\right)+\alpha_{C+} \kappa_{+}^{\text {off }}\left(\frac{P_{C+}^{\text {off }}}{N p}\right)\right] \\
& \times \rho H_{U}+\mu H_{C}, \\
& \frac{d H_{C}}{d t}=\left[\alpha_{C-} \kappa_{-}^{\mathrm{off}}\left(\frac{P_{C-}^{\mathrm{off}}}{N p}\right)+\alpha_{C-} \kappa_{-}^{\mathrm{on}}\left(\frac{P_{C-}^{\mathrm{on}}}{N p}\right)\right. \\
& \left.+\alpha_{C+} \kappa_{+}^{\text {on }}\left(\frac{P_{C+}^{\text {on }}}{N p}\right)+\alpha_{C+} \kappa_{+}^{\text {off }}\left(\frac{P_{C+}^{\text {off }}}{N p}\right)\right] \\
& \times \rho H_{U}-\mu H_{C} \text {. }
\end{aligned}
$$

\section{Conflict of Interests}

D. T. Grima and E. M. C. D'Agata have been consultants for and received research funding from Genzyme Corporation.

\section{Funding}

This work is financially supported by Genzyme Corporation.

\section{Acknowledgment}

The authors would like to acknowledge the contributions of Parisa Airia during the preparation of the paper.

\section{References}

[1] F. Barbut, G. Corthier, Y. Charpak et al., "Prevalence and pathogenicity of Clostridium difficile in hospitalized patients: a French multicenter study," Archives of Internal Medicine, vol. 156, no. 13, pp. 1449-1454, 1996.

[2] J. G. Bartlett, "Clostridium difficile: history of its role as an enteric pathogen and the current state of knowledge about the 
organism," Clinical Infectious Diseases, vol. 18, supplement 4, pp. S265-S272, 1994.

[3] L. K. Archibald, S. N. Banerjee, and W. R. Jarvis, "Secular trends in hospital-acquired Clostridium difficile disease in the United States, 1987-2001," Journal of Infectious Diseases, vol. 189, no. 9, pp. 1585-1589, 2004.

[4] V. G. Loo, L. Poirier, M. A. Miller et al., "A predominantly clonal multi-institutional outbreak of Clostridium difficileassociated diarrhea with high morbidity and mortality," The New England Journal of Medicine, vol. 353, no. 23, pp. 24422449, 2005.

[5] L. C. McDonald, G. E. Killgore, A. Thompson et al., "An epidemic, toxin gene-variant strain of Clostridium difficile," The New England Journal of Medicine, vol. 353, no. 23, pp. 2433-2441, 2005.

[6] M. D. Zilberberg, A. F. Shorr, and M. H. Kollef, "Increase in adult Clostridium difficile-related hospitalizations and casefatality rate, United States, 2000-2005," Emerging Infectious Diseases, vol. 14, no. 6, pp. 929-931, 2008.

[7] W. N. Al-Nassir, A. K. Sethi, Y. Li, M. J. Pultz, M. M. Riggs, and C. J. Donskey, "Both oral metronidazole and oral vancomycin promote persistent overgrowth of vancomycinresistant enterococci during treatment of Clostridium difficileassociated disease," Antimicrobial Agents and Chemotherapy, vol. 52, no. 7, pp. 2403-2406, 2008.

[8] E. J. Vollaard and H. A. L. Clasener, "Colonization resistance," Antimicrobial Agents and Chemotherapy, vol. 38, no. 3, pp. 409-414, 1994.

[9] E. M. C. D’Agata, S. Gautam, W. K. Green, and Y. W. Tang, "High rate of false-negative results of the rectal swab culture method in detection of gastrointestinal colonization with vancomycin-resistant enterococci," Clinical Infectious Diseases, vol. 34, no. 2, pp. 167-172, 2002.

[10] R. D. Poduval, R. P. Kamath, M. Corpuz, E. P. Norkus, and C. S. Pitchumoni, "Clostridium difficile and vancomycin-resistant Enterococcus: the new nosocomial alliance," The American Journal of Gastroenterology, vol. 95, no. 12, pp. 3513-3515, 2000.

[11] C. J. Donskey, A. J. Ray, C. K. Hoyen et al., "Colonization and infection with multiple nosocomial pathogens among patients colonized with vancomycin-resistant Enterococcus," Infection Control and Hospital Epidemiology, vol. 24, no. 4, pp. 242-245, 2003.

[12] A. L. Leber, J. F. Hindler, E. O. Kato, D. A. Bruckner, and D. A. Pegues, "Laboratory-based surveillance for vancomycinresistant enterococci: utility of screening stool specimens submitted for Clostridium difficile toxin assay," Infection Control and Hospital Epidemiology, vol. 22, no. 3, pp. 160-164, 2001.

[13] N. Scheinfeld and K. Biggers, "Tolevamer, an orally administered, toxin-binding polymer for Clostridium difficileassociated diarrhea," Current Opinion in Investigational Drugs, vol. 9, no. 8, pp. 913-924, 2008.

[14] P. L. Hinkson, C. Dinardo, D. DeCiero, J. D. Klinger, and R. H. Barker, "Tolevamer, an anionic polymer, neutralizes toxins produced by the BI/027 strains of Clostridium difficile," Antimicrobial Agents and Chemotherapy, vol. 52, no. 6, pp. 2190-2195, 2008.

[15] K. Garborg, B. Waagsbø, A. Stallemo, J. Matre, and A. Sundøy, "Results of faecal donor instillation therapy for recurrent Clostridium difficile-associated diarrhoea," Scandinavian Journal of Infectious Diseases, vol. 42, no. 11-12, pp. 857-861, 2010.

[16] S. S. Yoon and L. J. Brandt, "Treatment of refractory/recurrent C. difficile-associated disease by donated stool transplanted via colonoscopy: a case series of 12 patients," Journal of Clinical Gastroenterology, vol. 44, no. 8, pp. 562-566, 2010.

[17] A. A. MacConnachie, R. Fox, D. R. Kennedy, and R. A. Seaton, "Faecal transplant for recurrent Clostridium difficileassociated diarrhoea: a UK case series," QJMed, vol. 102, no. 11, pp. 781-784, 2009.

[18] "A overview of the current status of FDIT," Scientific American, November 2011, http://www.scientificamerican .com/article.cfm?id=swapping-erms\&page $=3 \#$ comments.

[19] E. M. C. D’Agata, G. Webb, and M. Horn, “A mathematical model quantifying the impact of antibiotic exposure and other interventions on the endemic prevalence of vancomycinresistant enterococci," Journal of Infectious Diseases, vol. 192, no. 11, pp. 2004-2011, 2005.

[20] C. A. Muto, J. A. Jernigan, B. E. Ostrowsky et al., "SHEA guideline for preventing nosocomial transmission of multidrugresistant strains of Staphylococcus aureus and Enterococcus," Infection Control and Hospital Epidemiology, vol. 24, no. 9, pp. 362-386, 2003.

[21] E. S. McBryde and D. L. S. McElwain, "A mathematical model investigating the impact of an environmental reservoir on the prevalence and control of vancomycin-resistant enterococci," Journal of Infectious Diseases, vol. 193, no. 10, pp. 1473-1474, 2006.

[22] H. Gbaguidi-Haore, S. Legast, M. Thouverez, X. Bertrand, and D. Talon, "Ecological study of the effectiveness of isolation precautions in the management of hospitalized patients colonized or infected with Acinetobacter baumannii," Infection Control and Hospital Epidemiology, vol. 29, no. 12, pp. 11181123, 2008.

[23] W. N. Al-Nassir, A. K. Sethi, M. M. Nerandzic, G. S. Bobulsky, R. L. P. Jump, and C. J. Donskey, "Comparison of clinical and microbiological response to treatment of Clostridium difficileassociated disease with metronidazole and vancomycin," Clinical Infectious Diseases, vol. 47, no. 1, pp. 56-62, 2008.

[24] D. N. Gerding, "Is there a relationship between vancomycinresistant enterococcal infection and Clostridium difficile infection?" Clinical Infectious Diseases, vol. 25, supplement, pp. S206-S210, 1997.

[25] A study to assess the safety, tolerability, effectiveness and absorption of Exodif tablets in Clostridium difficileassociated diarrhea. Trial identifier: NCT00466635, 2011, http://www.clinicaltrials.gov/.

[26] E. van Nood, P. Speelman, E. J. Kuijper, and J. J. Keller, "Struggling with recurrent Clostridium difficile infections: is donor faeces the solution?” Euro Surveillance, vol. 14, no. 34, Article ID 19316, 2009.

[27] L. O. Conterno, J. Shymanski, K. Ramotar, B. Toye, R. Zvonar, and V. Roth, "Impact and cost of infection control measures to reduce nosocomial transmission of extended-spectrum $\beta$ lactamase-producing organisms in a non-outbreak setting," Journal of Hospital Infection, vol. 65, no. 4, pp. 354-360, 2007.

[28] Y. Carmeli, G. Eliopoulos, E. Mozaffari, and M. Samore, "Health and economic outcomes of vancomycin-resistant enterococci," Archives of Internal Medicine, vol. 162, no. 19, pp. 2223-2228, 2002.

[29] C. D. Salgado and B. M. Farr, "Outcomes associated with vancomycin-resistant enterococci: a meta-analysis," Infection Control and Hospital Epidemiology, vol. 24, no. 9, pp. 690-698, 2003. 


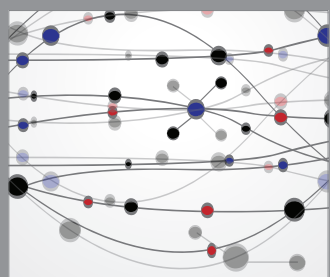

The Scientific World Journal
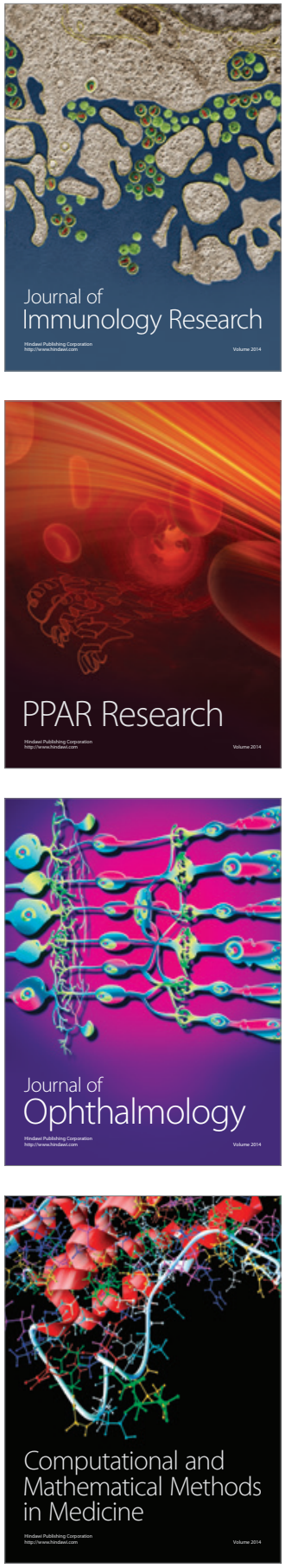

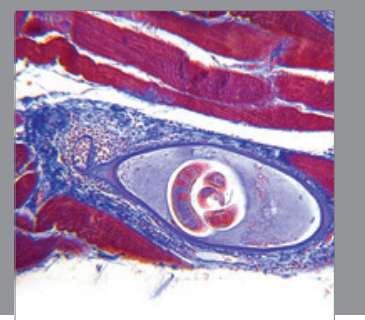

Gastroenterology

Research and Practice
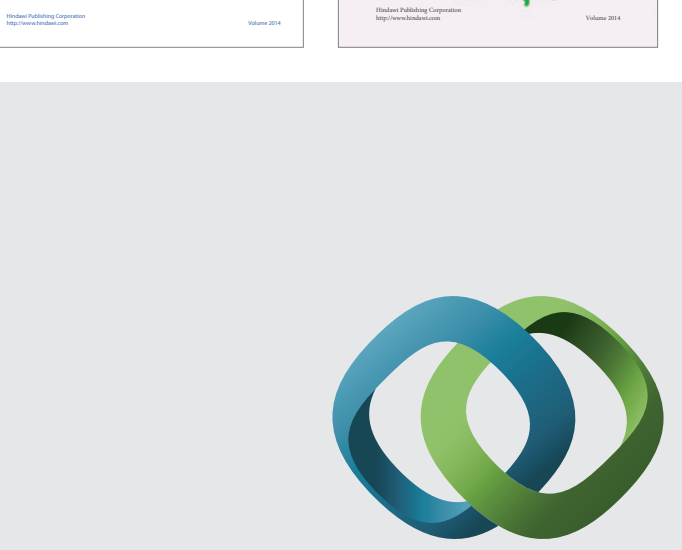

\section{Hindawi}

Submit your manuscripts at

http://www.hindawi.com
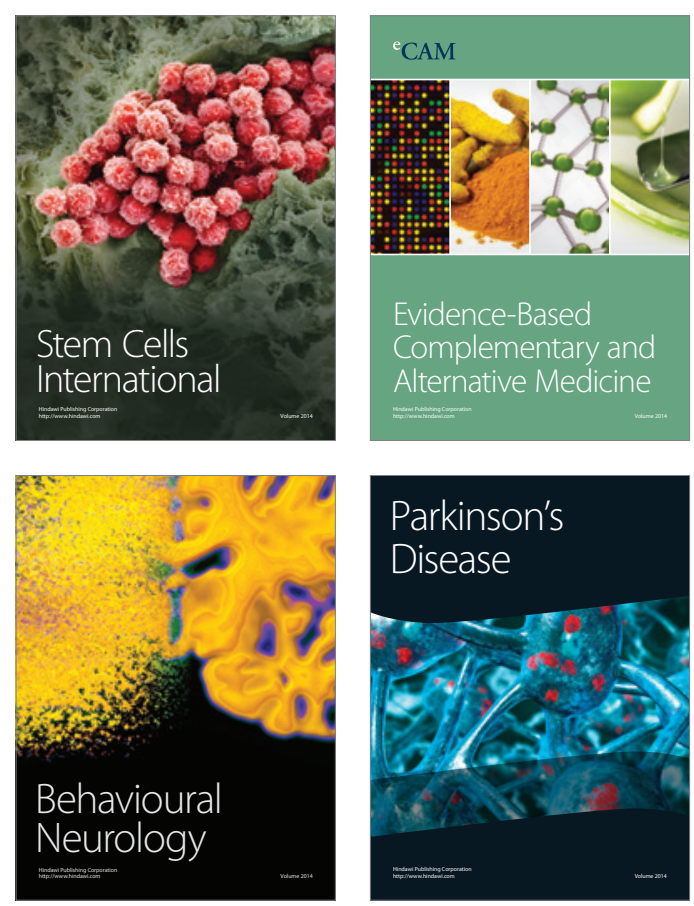

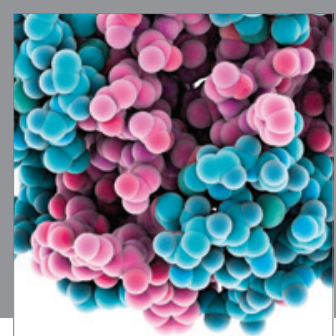

Journal of
Diabetes Research

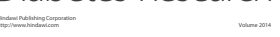

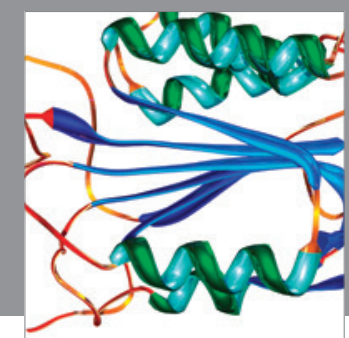

Disease Markers
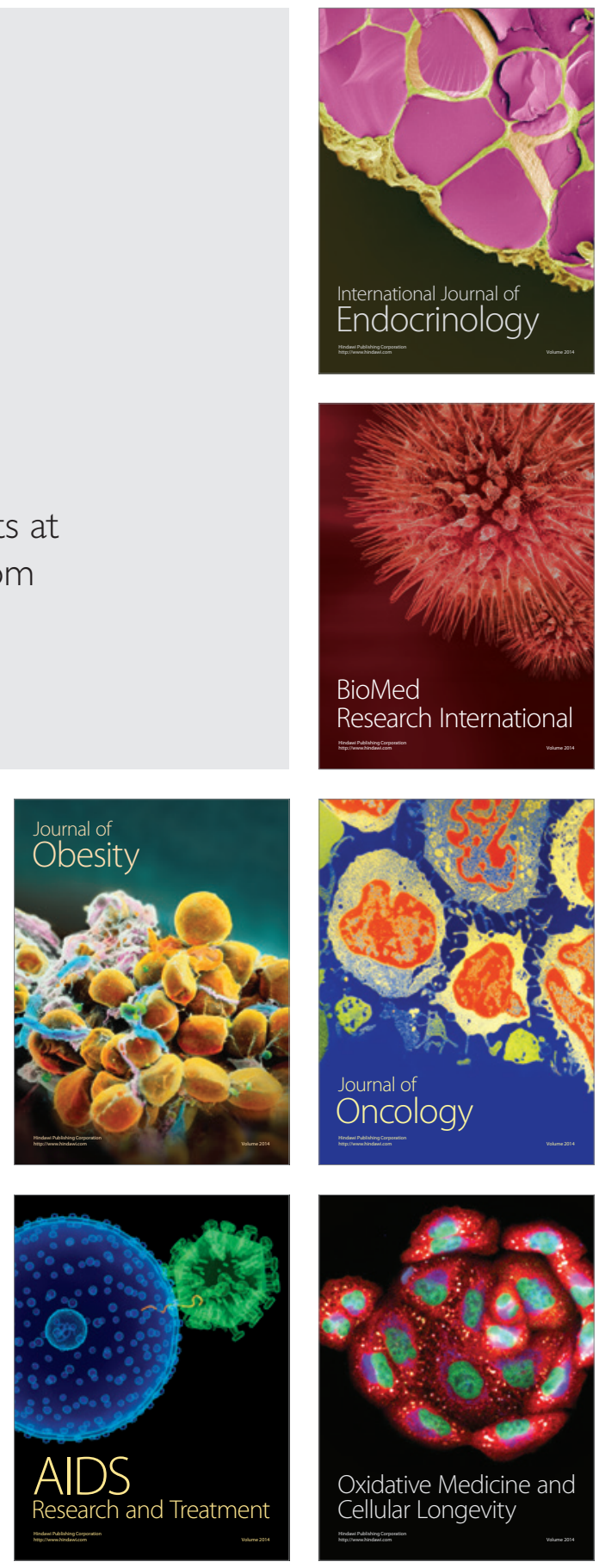